Schulich School of Law, Dalhousie University

Schulich Law Scholars

$1-31-2011$

Bad News about Bad News: The Disclosure of Risks to Insurability in Research Consent Processes

Victoria Smith Apold

Jocelyn Downie

Follow this and additional works at: https://digitalcommons.schulichlaw.dal.ca/scholarly_works

Part of the Bioethics and Medical Ethics Commons, and the Health Law and Policy Commons 


\section{Bad News about Bad News: The Disclosure of Risks to Insurability in Research Consent Processes}

\section{Victoria Smith Apold, LL.M., and Jocelyn Downie, S.J.D.}

\section{Faculty of Law and Medicine, Dalhousie University, Halifax, Nova Scotia, Canada}

One of the phenomena associated with research is "incidental findings," that is, unexpected findings made during the research, and outside the scope of the research, which have potential health importance. One underappreciated risk of incidental findings is the potential loss of the research subject's insurability; or if a research subject fails to disclose incidental findings when applying for insurance, the insurance contract may be voidable by the insurer. In this article, we seek to explain the insurability risks associated with incidental findings and to make recommendations for how researchers and research ethics committees should address the issue of disclosure of these risks.

Keywords: consent, incidental findings, insurability risks, neuroethics, research ethics

\section{INTRODUCTION}

When research is conducted on human participants, there is often a risk that there will be an incidental finding (IF), that is, "a finding concerning an individual research participant that has potential health or reproductive importance and is discovered in the course of conducting research but is beyond the aims of the study" (Wolf et al., 2008). An underappreciated risk of IFs is the potential loss of the research subject's insurability or insurance. In short, if an applicant for life insurance discloses IFs, the insurer may refuse to provide insurance or may provide the insurance but only with increased premiums. If the insurer proves that an applicant failed to disclose or misrepresented material facts about the IFs, then the life insurance contract may be voidable by the insurer.

In this article, we seek to correct for this underappreciation, to explain the insurability risks associated with IFs, and to make recommendations directed at researchers and 
research ethics committees (RECs) ${ }^{1}$ with respect to the drafting and review of consent forms. We do this through an in-depth analysis of the specific illustrative example of Magnetic Resonance Imaging (MRI) research scans on healthy subjects in Canada. We use MRI research as much of the concern raised about IFs in the literature and in practice has come (and will continue to come) in the context of MRI research. However, the analysis applies equally to IFs arising in other areas of research (e.g., other kinds of diagnostic imaging and genetic testing). We focus on Canada as this is the jurisdiction within which we work. However, the relevant laws in many other countries are sufficiently similar to Canada that the analysis can be carried over. The insurance principles with respect to the duty of disclosure upon applying for life insurance are generally applicable, and thus the recommendation made at the end of this article about what prospective participants should be told about the risks MRI research participation poses with respect to insurability are relevant and transferrable to other jurisdictions. ${ }^{2}$ In sum, restricting the lens to MRI research scans on healthy subjects in Canada makes for an article of narrow focus but broad applicability. ${ }^{3}$

\section{THE INSURED'S DUTY TO DISCLOSE INCIDENTAL FINDINGS TO INSURERS}

\section{Uberrimae Fidei and the Common Law Obligation to Disclose Material Incidental Findings to Insurers}

The starting point for any discussion of life insurance law is the fact that life insurance contracts, like all insurance contracts, are considered contracts of uberrimae fidei-the utmost good faith. The reason for this is that with life insurance, unlike many other contracts, the insured is in the position of knowing the facts relevant to the insurance risk, while the insurer is not. Specifically, the details of the insured's health condition are not necessarily known or discoverable to the insurer (Norwood and Weir, 2002). ${ }^{4}$ One implication of this contract status is that if an applicant for life insurance knows of an IF but fails to disclose or misrepresents a material fact about the finding, then the life insurance contract is voidable by the insurer ${ }^{5}$ for up to two years, after which the insurer must prove fraud to avoid the contract. ${ }^{6}$ Another implication is that the insurer is equally entitled to avoid the life insurance contract if there was an innocent misrepresentation of a material fact by the applicant insured. ${ }^{7}$ The Nova Scotia Court of Appeal in Cooperants Mutual Life Insurance Society v. Cameron, considered the case of a life insurance applicant who forgot to mention to the insurance company that she had previously been denied life insurance by another insurance company (Cooperants, 1992). The Court followed another Nova Scotia case, Blouin v. Maritime Life Assurance Company, on the issue of mistaken 
misrepresentation, stating that even innocent misrepresentation, with good faith, if material, can avoid the contract (Blouin, 1988).

The issue of nondisclosure or misrepresentation in an insurance contract often arises when, upon the insured's death, a claim is made by the beneficiary under the contract and the insurer discovers there was nondisclosure or misrepresentation at the time of the application for insurance (Norwood and Weir, 2002). Notably, the nondisclosure or misrepresentation does not have to be related in any way to the cause of death (Norwood and Weir, 2002). ${ }^{8}$ For instance, imagine a case in which a researcher makes an IF, a white spot on the frontal lobe, and tells the research subject that it could be something serious and should be followed up with more tests. The research subject does not mention the IF on his life insurance application. The insurer and the research subject enter into a life insurance contract. Four months later, the research subject dies of a heart attack, completely unrelated to the white spot in his brain. Assuming the failure to disclose the IF is found to be material to the insurance risk, even if unrelated to the cause of death, the life insurer can provide a refund on the premiums paid up until death and deny the life insurance beneficiary the payout of the life insurance.

It is also important to note that the duty of disclosure applies at the point of application for life insurance and persists up until the delivery of the policy (Norwood and Weir, 2002). Therefore, any IFs arising after the application, but before delivery of the policy, must still be disclosed. IFs arising after delivery of the policy are not subject to this duty of disclosure.

\section{The Statutory Obligation to Disclose Incidental Findings to Insurers}

Insurance legislation in Canada ${ }^{9}$ is also a source of legal obligations regarding disclosure by the insurance applicant: "An applicant for insurance and a person whose life is to be insured shall each disclose to the insurer in the application, on a medical examination, if any, and in any written statements or answers furnished as evidence of insurability, every fact within the person's knowledge that is material to the insurer and is not so disclosed by the other" 10 (emphasis ours). Canadian statute law thus requires that the applicant disclose to the insurer (i) facts, (ii) within his/her knowledge, (iii) which are material to the insurer's risk. ${ }^{11}$

\section{Facts}

With respect to the insured's duty to disclose facts, Norwood and Weir (2002, p. 383) state that the "duty is to disclose to the insurer the fact of all of their symptoms, consultations, and medical treatments or tests, regardless of the life insured's own belief as to their 
importance or significance or that they feel they are free of health problems." Thus, it is not up to the life insured to consider the relevance and importance of diagnoses or treatment recommendations to the insurer's risk assessment. The life insured must simply report the facts. 12

\section{Within His/Her Knowledge}

The "within his/her knowledge" part of the legal test is the one most affected by the knowledge of an IF. Even when the research subject experiences no symptoms related to the IF, if the IF is material, knowledge of the IF has to be disclosed to the insurer. Where there is an IF and the research subject is referred for further medical attention, even if the researchers feel a negative health outcome is highly unlikely, if the life insurance has not yet been delivered, the insured is under a duty to disclose the fact of this referral for further medical evaluation to the insurer. The fact of the referral and the reasons for it must be disclosed even if the results of the referral and follow-up are completely unknown at the time of the application and even if the end result could be that the IF is $100 \%$ benign. The IF may ultimately turn out to be nothing of any consequence to the research subject's health, but unless and until that is known, the applicant is under a duty to disclose the IF to the insurer.

The extent of the insured's duty of disclosure is usefully summarized by Norwood and Weir (2002, p. 381-382) as follows: "Non-disclosure or misrepresentation of a known event or information may have been due to negligence upon the part of the insured or life insured, where they meant to disclose it, but did not actually do so. It may have been due to forgetfulness of a medical consultation or their doctor's explanation of the nature of their medical condition. It may have been due to mistake, believing that they had disclosed it to the insurer upon a previous occasion, or they believed that the insurer was already in possession of the fact of its own knowledge. It may have been due to misjudgement on the life insured's part where they felt that the fact was not really significant and, therefore, did not consider it important to tell to the insurer. But in life insurance, a failure to disclose a known material fact, even innocently or through inadvertence or because the fact slipped the insured's memory, entitles the insurer to avoid the contract."

However, it should also be noted that "[i]f the insured or life insured never actually knew of the matter in dispute, they cannot be guilty of a misrepresentation sufficient to invalidate the contract, notwithstanding that the unknown fact is a material fact which would have caused the insurer to decline the risk" (Norwood and Weir, 2002, p. 381).

\section{Materiality}


Whether or not a fact is material to the insurance risk is assessed from the insurer's point of view not the insured's point of view (Norwood and Weir, 2002). In the leading case of Mutual Life Insurance Co. v. Ontario Metal Products Co., the court held that the materiality test looks at whether the reasonable insurer would have declined the risk or required a higher premium if the information had been disclosed (Mutual, 1925). ${ }^{13}$

In a case of contested coverage, an insurer has the onus to show not just that it would not have provided insurance at all or at that rate had the facts been disclosed to them, but also that a reasonable insurer would have declined the risk or required a higher premium. This objective test holds the insurer to a high standard in proving materiality.

In Henwood v. Prudential Insurance Co. of America, the supreme Court of Canada addressed the issue of the standard for the insurer for proving materiality (Henwood, 1967). In Henwood, the insured failed to disclose that she suffered from depression and anxiety. At a trial brought by the insured's estate to enforce her life insurance policy, the insurance company defended their claim on the basis of misrepresentation. The insurer's medical doctor testified, stating that if these facts had been disclosed they would have required a medical examination and further follow-up, and that ultimately they would have provided insurance at a very high rate. The insured did not provide any underwriting evidence to rebut this. Notably, the insurers did not adduce evidence about whether other insurers would find this issue to be material.

The majority of the Supreme Court of Canada in Henwood emphasized that there was no evidence brought to contradict the insurer's evidence on this issue throughout the judgment, concluding that the misrepresentations were material to the risk and that the policy could be voided by the insurer. The Court held that the insurer's own underwriting practices with respect to materiality were reasonable and that, since no evidence was adduced to prove otherwise, the insurer was not obliged to show the practice of other insurers. The majority distinguished the principle laid out in Mutual Life Insurance, on the basis that the insurer's doctor testified in the Mutual Life Insurance case that even if he had known about the insured's prior medical history (that was misrepresented on the application), he would still have recommended acceptance of the life insurance application.

\section{Conclusion}

In sum, if an applicant for life insurance has been told of an IF, then the applicant must disclose the IF to the insurer. Whether the disclosed fact (the IF) is material to the insurance risk, is assessed from the point of view of the reasonable insurer. An applicant's failure to meet this disclosure obligation can result in the insurance contract being void even where the IF ultimately has no bearing whatsoever on the person's death. 


\section{THE NATURE OF INCIDENTAL FINDINGS AND THEIR MATERIALITY TO REASONABLE INSURERS (FOR DECISIONS REGARDING COVERAGE OR PREMIUMS)}

Now we must ask, What is the nature of IFs? And, more specifically, can they be of such significance that they could affect a reasonable insurer's decision about whether to insure and at what premium? We must look at specific IFs that arise during various MRI scans in order to answer these questions. ${ }^{14}$

The prevalence of IFs in brain MRIs was recently quantified in a meta-analysis by Morris et al. (2009). The authors concluded that IFs are "common," that the prevalence increases along with age, and that detection of IFs is more likely with higher resolution MRI sequences. To arrive at these conclusions, the authors included 16 publications reporting data between 1989 and 2008 for a total of 19,559 people in their analysis. This metaanalysis included data arising from a number of different settings including clinical and research settings. The participants in the studies included in the meta-analysis did not have neurological or psychiatric symptoms.

Morris et al. (2009) divided the brain IFs into two clinically relevant categories: neoplastic (benign and malignant tumors) and non-neoplastic (cysts, structural vascular abnormalities, inflammatory lesions, and "other"). The authors found that overall, the prevalence of IFs on brain MRI was 2.7\%. This prevalence increased to $4.3 \%$ where subjects underwent at least one high resolution MRI sequence and decreased to $1.7 \%$ prevalence where subjects underwent only low resolution MRI sequences. The overall prevalence of $2.7 \%$ was a combination from prevalence of neoplastic IFs of .7\% and prevalence of non-neoplastic IFs of $2.0 \%$. Of the non-neoplastic IFs, the most common was arachnoid cysts (.5\%), and the next most common was aneurysms (.35\%).

The risks of IFs are not limited to brain MRI scans. A number of recent publications have highlighted IFs that are appearing during other MRI scans, for instance: whole body scans (Morin et al, 2009), cardiac MRI scans (McKenna et al., 2008), and MRI-enterography for the small intestine (Jensen et al., 2010).

Morin et al. (2009) recently published the results of their study looking at IFs in 148 healthy research subjects using whole-body MRI. The researchers classified the abnormalities into one of three categories based on their clinical significance: highly significant findings require prompt medical follow-up (e.g., indeterminate mass in solid organ, enlarged lymph nodes, ovarian mass/cyst); moderately significant findings might require further follow-up or treatment (e.g., gallstones, diverticulosis of the colon, 
unilateral renal agenesis); and low significance findings did not require further follow up or treatment (e.g., renal cysts, hepatic cysts).

Overall, out of the 148 healthy volunteers in the Morin et al. (2009) study, 43 subjects had at least one abnormality, with 6 subjects having two abnormalities, for a total of 49 abnormalities detected. This translates to the prevalence of IFs being $29.1 \%$ for the group of healthy volunteers in a whole-body MRI. Of the 49 abnormalities found, more than half, or $59.2 \%$, were deemed of low clinical significance, $30.6 \%$ were moderate significance, and $10.2 \%$ were high clinical significance. Overall, the prevalence of moderate and high IFs was $12.8 \%$. The authors noted that the prevalence of abnormal findings increased with the subjects' age and his/her body mass index.

In a research paper that examined the prevalence of IFs during cardiac MRI, there was another high rate of IFs noted by the authors. McKenna et al. (2008) used a cardiac magnetic resonance (CMR) which provides a view of the heart and vessels, along with the thorax and upper abdomen to conduct their study on the 132 participants. The authors divided their findings into three categories: clinically significant abnormalities that require further clinical or radiological follow-up (e.g., pulmonary nodule, solid renal mass or complex cyst, non-cystic liver lesion); intermediate significant abnormalities may affect patient care depending on the circumstances of the patient's health (e.g., aortic plaque, pleural effusion, gallstones); and benign abnormalities (e.g., renal cyst, scoliosis, degenerative disc disease).

McKenna et al. (2008) found $81 \%$ of the participants had at least one IF, with $48 \%$ of the participants having multiple abnormal findings; $17.4 \%$ of the participants had clinically significant abnormalities, with the most common IF being a pulmonary nodule in 5 patients. For intermediate significant findings, the most common IF was aortic plaque that was found in $15.2 \%$ of the participants.

There are an unlimited number of omissions or misrepresentations, which a reasonable insurer could find to decline the risk or require a higher premium, with each case being fact specific. There is a large body of case law in the area of misrepresentation and disclosure in life insurance. We present a few cases here to illustrate the types of information found to be material to the insurer's risk. In Wynter v. Equitable Life Insurance Co., the insured failed to disclose that he sought medical attention for chest pains and shortness of breath, as well as not disclosing that he had an abnormal electrocardiogram (Wynter, 1976). The Court ruled that the insurers were entitled to declare the policy void as there was a failure to disclose these material facts.

In Tanner v. Toronto Dominion Bank, the insured stated on his application form that he did not have a kidney disorder when in fact he did (Tanner, 2002). Four months later, he died from a heart attack. The Prince Edward Island (PEI) Trial Division held that the insurer was 
entitled to avoid the contract as the kidney disorder was within his knowledge and was material to the insurance.

In Thompson v. Maritime Life Assurance Co., the insured failed to disclose on her application that she had been treated for pulmonary embolism, for recurrent abdominal pain, and had four electrocardiograms, among other medical problems (Thompson, 2004). The insured was subsequently murdered. The Court held that the insured made deliberate false representations on her insurance application and dismissed the action brought by the insured's husband for proceeds of the life insurance.

In Lafreniere Estate v. Cumis Life Insurance Co., the insured failed to disclose abnormal test results requiring further investigation (Lafreniere, 1996). The facts in this case were egregious because the insured was given an appointment to immediately see a surgeon after receiving test results and, just prior to his appointment with the surgeon, filled out his life insurance application. The insured in Lafreniere Estate was found to have failed to disclose the material fact that he was going to have a diagnostic test the day he signed the insurance application, even though the results of that diagnostic test were not known at that time.

In Nuraney v. MBA Insurance Brokers Inc., an action by the beneficiary of the estate was dismissed because the insured was found to have not disclosed the fact of certain test results, even though the results of the tests were not available at the time of the application for insurance (Nuraney, 1989).

As the discussion at the beginning of this section demonstrates, IFs are a common issue in all types of MRI scans. The case law on misrepresentation demonstrates that the types of IFs noted are conditions that reasonable insurers could use to deny coverage or determine premium rates, as any number of them could be material to the insurance risk.

\section{THE RESEARCHER'S DUTY TO DISCLOSE RISKS TO INSURABILITY TO POTENTIAL RESEARCH SUBJECTS}

If research participants are not being told of IFs, then there is no need for them to disclose risks regarding insurability, as what they do not know, they are not obliged to disclose on an application for life insurance. However, for the purposes of this article, we assume that research participants will be told of IFs. ${ }^{15}$ Thus, the question of what to disclose to participants about the risks of participation to their insurability becomes critically important.

Given the earlier discussion of the participant's duty of disclosure to insurers and the fact that at least some IFs could be seen to be material to insurer's coverage and premium 
decisions, it can be concluded that participation in MRI research carries with it the risk that the discovery of an IF that may result in life insurance being unavailable or more expensive to the participant or, if the participant fails to disclose the IFs to the insurer, that the participant's life insurance will be voided. Given the importance of life insurance (access, cost, and non-voidability), this is a significant risk. ${ }^{16}$

Under both the common law and the Tri-Council Policy Statement: Ethical Conduct for Research Involving Humans (hereinafter TCPS), ${ }^{17}$ researchers have significant obligations with respect to the disclosure of risks to potential research participants (Hadskis, 2007). ${ }^{18}$ There are two leading cases under the common law of informed consent for research participants: Halushka v. University of Saskatchewan and Weiss v. Solomon. The Court in Halushka ruled that a research participant "is entitled to a full and frank disclosure of all the facts, probabilities and opinions which a reasonable man might be expected to consider before giving his consent" (Halushka, 1965). The Court also ruled that the duty owed to research participants "is at least as great as, if not greater than, the duty owed by the ordinary physician or surgeon to his patient." The Halushka decision came down from the Saskatchewan Court of Appeal in 1965, before the leading cases in Canada on informed consent in the medical context. 19

The other leading case in Canada on the standard of informed consent for research participants is Weiss v. Solomon decided in 1989 after the leadings cases on informed consent in the medical treatment context (Weiss, 1989). In Weiss, the Quebec superior Court held: "[T] he duty to inform in [research involving no anticipated therapeutic benefits to participants] is the most exacting possible. All risks must be disclosed, even those which are rare or remote, especially if they entail serious consequences." 20 The Court in Weiss set a very high standard for researchers by requiring that all of the potential risks be disclosed to research participants.

Similarly, the TCPS sets out the requirements for free and informed consent in Section 2. Researchers are obliged to provide "full and frank disclosure of all information relevant to free and informed consent" (TCPS, Art. 2.4). As part of obtaining consent from subjects, Article 2.4(c) requires the researchers to provide: "A comprehensive description of reasonably foreseeable harms and benefits that may arise from research participation." The risks of being denied life insurance or facing higher premiums or of having one's insurance contract voided are significant. Therefore, researchers have an obligation to clearly explain to potential research participants the potential threats to their insurability and insurance posed by participation in MRI research. 


\section{RECOMMENDATIONS FOR MEETING DISCLOSURE OBLIGATIONS ABOUT RISKS TO PARTICIPANTS' INSURABILITY}

Not much is known about how Research Ethics Boards (REBs) across Canada handle IFs in MRI research generally, nor the disclosure of the risks of IF as they relate to insurability specifically. The best available (although limited) information on this comes from a study of Canadian REBs which examined the MRI project files from nine REBs to gather information about how they classify risk in MRI research and how they address harms (Marshall and Hadskis, 2009). In only two of the 37 MRI project files reviewed, subjects' insurability was one of the harms considered by the researchers or REBs (Hadskis and Marshall, Unpublished). In these two studies, the participant consent forms simply state that knowledge of an IF could affect their insurance premium (Hadskis and Marshall, Unpublished).

For this article, a random sample of Web-available consent forms for MRI studies was also reviewed. ${ }^{21}$ This search of online consent forms did not reveal a single form that disclosed risks to participant insurability. Most, but not all, of the consent forms referenced the chance of IFs, but not anything related to insurability. ${ }^{22}$ Both of these (admittedly methodologically-limited) investigations highlight the need for recommendations for wording in this area to be generated and disseminated so that researchers can better meet their disclosure obligations and RECs can better ensure that potential participants are receiving adequate disclosure. Based on the discussion in the previous sections of this article, we recommend that RECs require that consent forms for MRI research contain more information about insurability.

There are detailed discussions on this and other risks associated with IFs in MRI scans in the literature, including the physical, psychological, psychosocial, and financial risks associated with them (Downie et al., 2007; Royal and Peterson, 2008; Illes et al., 2008; Hoggard et al., 2009). We recommend specifically that RECs require inclusion of text along the following lines in the section of the consent form on potential harms:

If the researchers find an IF, this might affect your insurability. Applicants for insurance are required to disclose all facts within their knowledge that might affect a reasonable insurer's decisions about whether to provide insurance or what premiums to charge for insurance. If you apply for insurance or for reinstatement of insurance before an IF has been investigated and any problem ruled out, or if an IF turns out to reveal a condition or abnormality, you may not be able to get insurance or you may only be able to get insurance at a higher price than if you didn't know about the IF. If you do not disclose IFs, your insurance contract may be voidable by the insurance company (i.e., it may not have to pay your benefits). 
Inclusion of such text will contribute to a better understanding by potential research participants of the insurability risks associated with participating in the research and will thereby enhance the quality of the informed consent processes and results.

\section{ACKNOWLEDGMENTS}

The authors are grateful to the Institute of Neurosciences, Mental Health and Addiction (INMHA) of the Canadian Institutes of Health Research (CIHR) for their generous financial support through the Neuroethics New Emerging Team (NET) grant. The authors would like to thank Lorraine Lafferty for her comments on an earlier version of this article.

\section{Notes}

1. Different jurisdictions use different labels for entities tasked with the ethical oversight of research (for example, Institutional Review Board [IRB], Research Ethics Board [REB], and REC). For the purposes of this article, we use the most generic label, REC, so as to not limit the apparent relevance of the topic or targets of the recommendations.

2. In order to aid the reader in other jurisdictions to transfer our analysis and recommendations, references for relevant legislation and common law in the United Kingdom, United States, and Australia are provided throughout this article. Also, where differences arise, as between jurisdictions, these differences are highlighted.

3. The scope of this article is further limited insofar as we only look at the law as it is now. Hence we do not address the ethical question of whether the law is as it should be (e.g., is it ethically defensible that even innocent misrepresentation enables the policy to be voidable by the insurer?). Nor do we address the pragmatic question of how the law may need to be changed if, at some point in the future, the development and use of technology is such that IFs become extremely common. While interesting, these must remain questions for other articles.

4. The principle of uberrimae fidei is widely applicable to life insurance law across many jurisdictions. For instance, in Australia, this duty of the utmost good faith is codified in the Insurance Contracts Act 1984, s. 13. In the United States, there is also a positive duty on the insured to disclose all material facts (Dobbyn, 1996). However, many states have legislation on this issue that modifies the general common law principle. In the United Kingdom, the principle of uberrimae fidei also applies to insurance contracts. At the application stage, it requires both parties to not misrepresent material facts and confers the obligation to disclose material facts even if the question is not asked (http://www.lawcom.gov.uk/insurance_contract.htm). The duty of good faith is also codified in the U.K.'s Marine Insurance Act 1906, s. 17. 
5. Voidable means the contract continues to be in force unless and until it is avoided by the party entitled to rescind it, which retroactively nulls the contract (Norwood and Weir, 2002).

6. Insurance Act, s. 183(2): "Subject to section 184, a failure to disclose, or a misrepresentation of, such a fact renders the contract voidable by the insurer."Section 184(2) states: “... where a contract has been in effect for two years during the lifetime of the person whose life is insured, a failure to disclose or a misrepresentation of a fact required to be disclosed by section 183 does not, in the absence of fraud, render the contract voidable."Insurance is within provincial jurisdiction. Similar statutory provisions exist in other provinces. There is a large body of case law on the issue of what constitutes fraud. See, for example, Kruska (1985).

7. The law in the United States with respect to innocent misrepresentation in life insurance requires bad faith by the insured in withholding material information to void the policy (Dobbyn, 1996).

8. The reasoning behind this is that, if the material fact was disclosed at the time of the application, the insurer would not have entered into the contract and, therefore, would not bear the risk, regardless of the good intentions of the applicant. See, for example, Thompson (2004).

9. The common law regarding insurance law was superseded in many respects by the introduction of a uniform statute law in the common law jurisdictions in Canada in 1925 (http://www.fin.gc.ca/toc/1999/health-eng.asp).

10. Insurance Act, s. 183 (emphasis ours). This wording is the same across all common law provinces per the Uniform Life Insurance Act. The Civil Code of Quebec provides similarly (Art. 2408 C.C.Q.): "The client, and the insured if the insurer requires it, is bound to represent all the facts known to him which are likely to materially influence an insurer in the setting of the premium, the appraisal of the risk or the decision to cover it..."Note that this same duty also applies upon reinstatement of a lapsed policy: Ontario's Insurance Act, s. 189(4): "Sections 183 and 184 apply with necessary modifications to reinstatement of a contract."

11. In Australia, for instance, the insured's duty of disclosure upon application for insurance is to disclose "every matter that is known to the insured" that either the insured or a reasonable person in the circumstances "knows to be a matter relevant to the decision of the insured to accept the risk" (Insurance Contracts Act, 1984, s. 21).

12. This principle applies equally in the United States (Dobbyn, 1996). 
13. In the United Kingdom, the materiality test is as follows: "A representation is material which would influence the judgment of a prudent insurer in fixing the premium, or determining whether he will take the risk" (Marine Insurance Act, 1906, s. 20(2)).

14. A similar analysis could be run with the specifics of IFs in the context of other kinds of research.

15. This is, of course, a point of controversy in the literature. We do not enter into that debate here but rather proceed on the assumption that the arguments in support of disclosing IFs to participants will win out (as, for reasons we cannot go into here, we think they should).

16. Life insurance is a common financial planning tool used by many. The Canadian Life and Health Insurance Association (CLHIA), a voluntary trade association whose membership accounts for $99 \%$ of the life and health insurance in force in Canada, estimates that by the end of 2008, approximately 7.7 million people in Ontario owned \$1.4 trillion of life insurance. (www.clhia.ca/prov/facts2008_0N.pdf). Total ownership of life insurance in Canada is estimated to be $\$ 3.3$ trillion with an estimated 20 million plus Canadians owning life insurance (www.clhia.ca/download/KeyStats2009_EN.pdf). The issue of life insurance is, therefore, clearly of great importance to many people.

17. The TCPS is the document which establishes the standards for research ethics for research conducted in institutions receiving funding from one or more of the Canadian Institutes of Health Research, the Natural Sciences and Engineering Research Council, and the Social Sciences and Humanities Research Council. The goal is "to promote the ethical conduct of research involving human subjects” (TCPS, Introduction).

18. In the United States, the "Common Rule" sets out the legal standards for the protection of human research subjects. The standards prescribed apply to all government funded research involving human subjects (Title 45 Code of Federal Regulations, Part 46, (45 CFR 46) Subpart A). It also applies to research conducted in an institution that receives federal funds for research, even if specific research is not funded by federal agencies (Hadskis, 2007).

19. Hopp (1980), Reibl (1980). The modified objective standard espoused in Hopp and Reibl, arguably a higher standard than the objective test set out in Halushka, would more likely be applicable today. See Hadskis (2007, pp. 287-288) for a full discussion of this issue.

20. Hadskis (2007, p. 289), quoting from Picard and Robertson (1996, p. 150).

21. For example, MRI research consent forms found at the following sites were reviewed: http://www.brainnrg.ca/index.php?section=507; 
http://research.bmap.ucla.edu/sample_consent.html;

http://www.queensu.ca/neurosci/MRI/Templates/subject_information_template.doc; http://www.welcomebackcentre.com/files/documents/MRI-consent.pdf;

http://www.mni.mcgill.ca/files/staff/MRResearch.engconsentrevisedmay08.pdf

22. With respect to IFs, some of the sample wording stated: "Although this is not a diagnostic scan and any images obtained are for research purposes only, it is possible that the MR scan may disclose an unknown abnormality. In this event, a medical imaging specialist will be asked to review the images and we would send a report to your physician. The researchers directly involved with this procedure do not have the credentials to diagnose medical conditions." "... in the unlikely event that we note an atypical finding on your MRI scan, we will contact you to help you arrange medical follow-up to interpret the significance of the findings, if any. We may ask a radiologist, or other health professional, to look at your scan, and by signing this consent form you agree to releasing the scan for review. It is possible that you could be unnecessarily worried if a problem were suspected, but not actually found."

\section{REFERENCES}

\section{Art. 2408 C.C.Q.}

Blouin v. Maritime Life Assurance Company. (1988). 88 N.S.R. (2d) 23 (T.D.).

Cooperants Mutual Life Insurance Society v. Cameron. (1992). 118 N.S.R. (2d) 64 (C.A.).

Dobbyn, J. F. 1996. Insurance Law in a Nutshell, 3rd, St. Paul, MN: West Pub. Co.

Downie, J., Schmidt, M., Kenny, N., D'Arcy, R., Hadskis, M. and Marshall, J. 2007. Pediatric MRI research ethics: The priority issues. Bioethical Inquiry, 4: 85-91. [CrossRef], [Web of Science $\left.{ }^{\circledR}\right]$

Hadskis, M. 2007. "The regulation of human biomedical research in Canada". In Canadian Health Law and Policy, 3rd, Toronto: Butterworths.

Hadskis, M. and Marshall, J. Scanning the issues: Incidental findings in magnetic resonance imaging research, Manuscript on file with the authors. (Unpublished)

Halushka v. University of Saskatchewan. (1965). 53 D.L.R. (2d) 426 (Sask. C.A.).

Henwood v. Prudential Insurance Co. of America. (1967). S.C.R. 720. 
Hoggard, N., Darwent, G., Capener, D., Wilkinson, I. D. and Griffiths, P. D. 2009. The high incidence and bioethics of findings on magnetic resonance brain imaging of normal volunteers for neuroscience research. Journal of Medical Ethics, 35: 194-199.

[CrossRef], [PubMed], [Web of Science $\left.{ }^{\circledR}\right]$

Hopp v. Lepp 2 S.C.R. 1921980

Illes, J., Kirschen, M. P., Edwards, E., Bandettini, P., Cho, M. K., Ford, P. J., Glover, G. H., Kulynych, J., Macklin, R., Michael, D. B., Wolf, S. M., Grabowski, T. and Seto, B. 2008. Practical approaches to incidental findings in brain imaging research. Neurology, 70(5): 384-390. [CrossRef], [PubMed], [Web of Science ®]

Insurance Act, R.S.O., c.I.8. (1990). (Can.).

Insurance Contracts Act. (1984). (Cth.).

Jensen, M. D., Nathan, T., Kjeldsen, J. and Rafaelsen, S. R. 2010. Incidental findings at MRI-enterography in patients with suspected or known Crohn's disease. World Journal of Gastroenterology, 16(1): 76-82. [PubMed], [Web of Science ${ }^{\circledR}$ ]

Kruska v. The Manufacturers Life Insurance Company. (1985). 63 B.C.L.R. 209 (C.A.).

Lafreniere Estate v. Cumis Life Insurance Co. (1997). I.L.R. I-3422 (Ont.Gen.Div.).

Marine Insurance Act. (1906). 6 Edw. 7, c.41.

Marshall, J. and Hadskis, M. R. 2009. Canadian Research Ethics Boards, MRI Research Risks, and MRI Risk Classification. IRB: Ethics and Human Research, 31(4): 9-15.

McKenna, D. A., Laxpati, M. and Colletti, P. M. 2008. The prevalence of incidental findings at cardiac MRI. The Open Cardiovascular Medicine Journal, 2: 20-25. [CrossRef], [PubMed]

Morin, S. H. X., Cobbold, J. F. L., Lim, A. K. P., Eliahoo, J., Thomas, E. L., Mehta, S. R., Durighel, G., Fitzpatrick, J., Bell, J. D. and Taylor-Robinson, S. D. 2009. Incidental findings in health control research subjects using whole-body MRI. European Journal of Radiology, 72: 529-533. [CrossRef], [PubMed], [Web of Science ${ }^{\circledR}$ ]

Morris, Z., Whiteley, W. N., Longstreth, W. T., Weber, F., Lee, Y., Tsushima, Y., Alphs, H., Ladd, S. C., Warlow, C., Wardlaw, J. M. and Salman, R. A. 2009. Incidental findings on 
brain magnetic resonance imaging: systematic review and meta-analysis. BMJ, 339: b3016 [CrossRef], [PubMed], [Web of Science $\left.{ }^{\circledR}\right]$

Mutual Life Insurance Co. v. Ontario Metal Products Co. (1925). A.C. 344 (P.C.).

Norwood, D. and Weir, J. P. 2002. Norwood on Life Insurance Law in Canada, 3rd, Toronto: Carswell.

Nuraney v. MBA Insurance Brokers Inc. et al. (1989). I.LR. 1-2439 (Ont. H.C.).

Picard, E. and Robertson, G. 1996. Legal Liability of Doctors and Hospitals in Canada, 3rd, Scarborough, ON: Carswell.

Reibl v. Hughes. (1980). 2 S.C.R. 880.

Royal, J. M. and Peterson, B. S. 2008. The risks and benefits of searching for incidental findings in MRI research scans. Journal of Law, Medicine \& Ethics, 36(2): 305-314. [CrossRef], [Web of Science ${ }^{\circledR}$ ]

Tanner v. Toronto Dominion Bank. (2002). 212 Nfld. \& P.E.I.R. 211 (P.E.I.T.D.).

Thompson v. Maritime Life Assurance Co. (2004). 190 Man.R. (2d) 130 (C.A.).

Title 45 Code of Federal Regulations, Part 46, Subpart A.

1998. Tri-Council Policy Statement: Ethical Conduct for Research Involving Humans, Ottawa: Public Works and Government Services Canada.

Weiss v. Solomon. (1989) 48 C.C.L.T. 280 (Que. S.C.).

Wolf, S. M., Lawren, F. P., Nelson, C. A., Kahn, J. P., Cho, M. K., Clayton, E. W., Fletcher, J. G., Georgieff, M. K., Hammerschmidt, D., Hudson, K., Illes, J., Kapur, V., Keane, M. A., Koenig, B. A., LeRoy, B. S., McFarland, E. G., Paradise, J., Parker, L. S., Terry, S. F., Van Ness, B. and Wilfond, B. S. 2008. Managing incidental findings in human subjects research: Analysis and recommendations. Journal of Law, Medicine \& Ethics, 36(2): 219-248. [CrossRef], [PubMed], [Web of Science ${ }^{\circledR}$ ]

Wynter v. Equitable Life Insurance Co. (1976). I.L.R. 1-753 (Ont. H.C.). 